\title{
Thyroid hormone is highly permissive in angioproliferative pulmonary hypertension in rats
}

\author{
Aysar Al Husseini*, Gianluca Bagnato*, Laszlo Farkas*, Jose Gomez-Arroyo*, \\ Daniela Farkas*, Shiro Mizuno*,\#, Donatas Kraskauskas*, Antonio Abbate ${ }^{\natural}$, \\ Benjamin Van Tassel ${ }^{\mp}$, Norbert F. Voelkel* and Harm Jan Bogaard ${ }^{+}$
}

ABSTRACT: Epidemiological evidence links pulmonary arterial hypertension (PAH) with thyroid disease, but a mechanistic explanation for this association is lacking.

Because a central hallmark of vascular remodelling in pulmonary hypertension is lumen obliteration by endothelial cell growth and because thyroid hormones are known to be angiogenic, we hypothesised that thyroid hormones play a role in the control of endothelial cell proliferation in experimental PAH in rats.

Hypothyroidism was induced by subtotal thyroidectomy and treatment with propylthiouracil (PTU) in rats with experimental PAH after combined exposure to vascular endothelial growth factor receptor inhibition and hypoxia (the Sugen-chronic hypoxia (SuHx) model). Subtotal thyroidectomy prevented and PTU treatment reversed the development of severe experimental $\mathrm{PAH}$. Thyroxin repletion restored the PAH phenotype in thyroidectomised SuHx rats. The prevention of $\mathrm{PAH}$ by thyroidectomy was associated with a reduced rate of cell turnover, reduced extracellular signal-regulated protein kinases 1 and 2 phosphorylation, and reduced expression of $\alpha_{v} \beta_{3}$ integrin, fibroblast growth factor (FGF)-2 and FGF receptor. Thyroidectomy mitigated hypoxia-induced pulmonary hypertension, but this effect was not associated with a decreased pulmonary vascular resistance.

These data suggest that thyroid hormone permits endothelial cell proliferation in PAH. A causal link between thyroid diseases and the onset or progression of vascular remodelling in PAH patients remains to be determined.

KEYWORDS: Angiogenesis, integrins, pulmonary circulation, thyroid hormone

hronic pulmonary arterial hypertension (PAH) is characterised by pulmonary vascular remodelling involving the smooth muscle cells of the media and growth of phenotypically altered endothelial cells [1, 2]. Many forms of severe chronic PAH are refractory to treatment with vasodilator drugs [3] and the overall mortality remains high. It appears that in many $\mathrm{PAH}$ patients, the pre-capillary arterioles are obliterated by apoptosis-resistant endothelial cells via a process resembling angiogenesis [4]. Severe forms of $\mathrm{PAH}$ have been classified as idiopathic, heritable, drug- and toxin-induced and associated $[5,6]$. Examples of associated forms are $\mathrm{PAH}$ in connective tissue disease, HIV infection, sarcoidosis and sickle cell disease [7-9]. A large number of PAH patients also have thyroid disease [10], but it is unclear whether this association between PAH and thyroid disease is coincidental or relates to an aetiological role of thyroid hormones in the development of PAH. Thyroid hormones stimulate endothelial cell growth [11-13] and enhance hypoxic pulmonary vasoconstriction [14], and we therefore hypothesised that thyroid disease can affect pulmonary vascular remodelling in the setting of chronic PAH. We used the Sugenchronic hypoxia $(\mathrm{SuHx})$ rat model of severe angioproliferative PAH [15-17], which depends on two hits: the induction of initial lung endothelial cell apoptosis by the vascular endothelial growth factor (VEGF) receptor tyrosine kinase inhibitor SU5416, and the cell growth-promoting chronic exposure to hypoxia. Here we show for the first time that thyroid hormones are highly

\section{AFFILIATIONS}

*Pulmonary and Critical Care Medicine Division and Victoria Johnson Center for Pulmonary Ocbstructive Research, Virginia Commonwealth University, and 'Division of Cardiology, Virginia Commonwealth University, Richmond, VA, USA. \#Dept of Pulmonary Medicine, Kanazawa Medical University, Kanazawa, Japan.

+Dept of Pulmonary Medicine, VU University Medical Center, Amsterdam, The Netherlands.

CORRESPONDENCE

H.J. Bogaard Dept of Pulmonary Medicine VU University Medical Center P0 Box 7057

1007 MB

Amsterdam

The Netherlands

E-mail: hj.bogaard@vumc.nl

Received:

Nov 112011

Accepted after revision:

April 202012

First published online:

July 262012 
permissive for both pulmonary hypertension ( $\mathrm{PH}$ ) and formation of lumen obliterating lung vascular lesions.

\section{METHODS}

Subtotal thyroidectomised Sprague-Dawley rats used in this study were purchased from Harlan Laboratories (Frederic, MD, USA). $5 \mathrm{mg}$ of thyroxin was prepared in 60-day release pellets (Innovative Research of America, Sarasota, FL, USA). Severe angioproliferative $\mathrm{PAH}$ and right heart failure was induced in male Sprague-Dawley rats (bodyweight $200 \mathrm{~g}$ and age 6 weeks) through their exposure to the VEGF receptor antagonist SU5416 and SuHx, as described previously [16, 17]. One subset of thyroidectomised rats was given the $\mathrm{SuHx}$ combination starting 2 weeks after the thyroidectomy surgery and another one was given the thyroxin pellet subcutaneously 2 days before starting with the SuHx exposure. In another subset of SuHx animals, propylthiouracil (PTU; $10 \mathrm{mg} \cdot \mathrm{kg}^{-1}$ per day; Sigma, St. Louis, MO, USA) was administered subcutaneously (s.c.) 5 days $^{*}$ week $^{-1}$ for 4 weeks starting 2 weeks after establishing the PAH model. Finally, the effects were studied of thyroidectomy on pulmonary vascular remodelling and haemodynamics after 4 weeks of chronic exposure to hypoxia (inspiratory oxygen fraction 10\%). Cardiac ultrasound, haemodynamic measurements, tissue harvest and processing were performed as described previously. Cardiac output and stroke volume were indexed for body surface area (calculated from bodyweight [18]), yielding cardiac index (CI) and stroke index, respectively. Pulmonary vascular resistance index (PVRI) was calculated as:

\section{$80 \times(\mathrm{mP}$ pa-LVEDP $) / \mathrm{CI}$}

where $\mathrm{m} P$ pa is mean pulmonary artery pressure and LVEDP is left ventricular end-diastolic pressure. In those instances where catheter advancement into the pulmonary artery was not possible (approximately one out of every eight rats), mean $P$ pa was estimated from right ventricular systolic pressure (RVSP), as described previously [19]. Further details for animal models, assessment of angioproliferative vascular lesions, immunohistochemistry, Western blot analysis and statistical analysis are available in the online supplementary material.

\section{RESULTS \\ $\mathrm{PH}$ and pulmonary vascular remodelling in the SuHx rat model of severe $\mathrm{PH}$ are prevented by thyroidectomy}

To address the question of whether thyroid hormones contribute to the development of PAH and pulmonary vascular remodelling in the SuHx model, we assessed whether subtotal thyroidectomy prevented the development of haemodynamic and lung histological changes characteristic of this model. Euthyroid and thyroidectomised rats were exposed to a single dose of the VEGF receptor tyrosine kinase inhibitor SU5416 (25 mg. $\mathrm{kg}^{-1}$ s.c.) and hypoxia for 4 weeks, a sufficient exposure time to generate severe vaso-obliterative PAH [15]. As can be seen from figure 1, thyroidectomy prevented an increase in RVSP in response to SuHx. The reduction in RVSP after thyroidectomy of SuHx rats was not only related to a decreased CI, an expected finding in hypothyroid animals, but was also, to a large extent, attributed to a decreased PVRI. Thyroxin levels were decreased, as expected, in the subtotal thyroidectomy group and thyroxin levels closely correlated with RVSP values. Development of PH was associated with an abnormal Doppler signal in the pulmonary artery and a progressive shortening of the pulmonary artery acceleration time (fig. S1). Thyroidectomy prevented these changes in Doppler signal. The prevention of $\mathrm{PH}$ in the thyroidectomised SuHx rats was paralleled by prevention of right ventricular (RV) dilatation and hypertrophy. Supplemental thyroxin restored physiological levels of thyroxin in the thyroidectomised SuHx rats, which led to restoration of RVSP and PVRI to the levels seen in the euthyroid SuHx rats. Whereas a large number of arterioles were either completely or partially occluded in the lungs from SuHx rats treated with $\mathrm{SuHx}$ (fig. 2a and b), thyroidectomy resulted in a lung histology characterised by patent but muscularised arterioles (fig. $2 \mathrm{c}$ and d). Supplementation of thyroxin in thyroidectomised SuHx animals permitted PAH-characteristic vessel obliteration (fig. 2e and f). The numbers of partially patent and fully lumen obliterated vessels (in per cent) is shown in figure $2 \mathrm{~g}$ and the percentage of patent vessels was correlated with RVSP (fig. 2h). Because hypoxia can affect the secretion of thyroid hormones and can also cause changes in plasma levels of thyroxin [20-22], we tested whether the combination of SU5416 plus administration of thyroxin (however, without hypoxia) caused pulmonary vascular remodelling and $\mathrm{PH}$. Our data demonstrate that chronic administration of thyroxin alone only causes mild PH in SU5416-treated rats (fig. S2). Thus, chronic thyroxin supplementation without hypoxia does not reproduce the pulmonary vascular disease observed in the SuHx model.

\section{The effect of thyroidectomy on hypoxic pulmonary vascular remodelling}

Persistence of a certain degree of medial wall thickening after thyroidectomy (fig. 2) suggested that the lack of thyroid hormone mainly affected the obliteration of lung vessels in thyroidectomised SuHx rats. To determine whether thyroid hormones also affect the degree of muscularisation, we subsequently exposed normal and thyroidectomised rats to chronic hypoxia alone (a model of medial wall thickening but not vascular occlusions), without concomitant SU5416 administration (fig. 3). Thyroidectomy decreased media wall thickness and lowered RVSP after hypoxic exposure, but the reduction in PVRI was statistically not significant and was not associated with a reduced RV hypertrophy. Chronic hypoxic exposure led to an expected increase in haematocrit of $20-30 \%$ and this increase was not affected by thyroidectomy.

\section{Thyroidectomy decreased or inhibited the expression of cell proliferation and cell death markers in the lungs from SuHx animals}

To assess whether thyroidectomy prevented lesion cell growth we used immunohistochemistry (IHC) to localise the expression of proliferating cell nuclear antigen (PCNA) (fig. S3) and the same lung tissues protein lysates were analysed by western blot (fig. 4). Because the development of angio-obliterative lesions in the SuHx model depends also on lung cell death [16], we assessed cleaved caspase 3 expression in lung tissue by IHC (fig. S3) and western blot (fig. 4). PCNA-positive cells were found abundantly in the examined tissue sections of SuHx lungs and both IHC and western blot showed that the expression of PCNA was reduced in the lungs from thyroidectomised SuHx animals when compared with lungs from euthyroid SuHx rats. In addition, thyroidectomy reduced the 

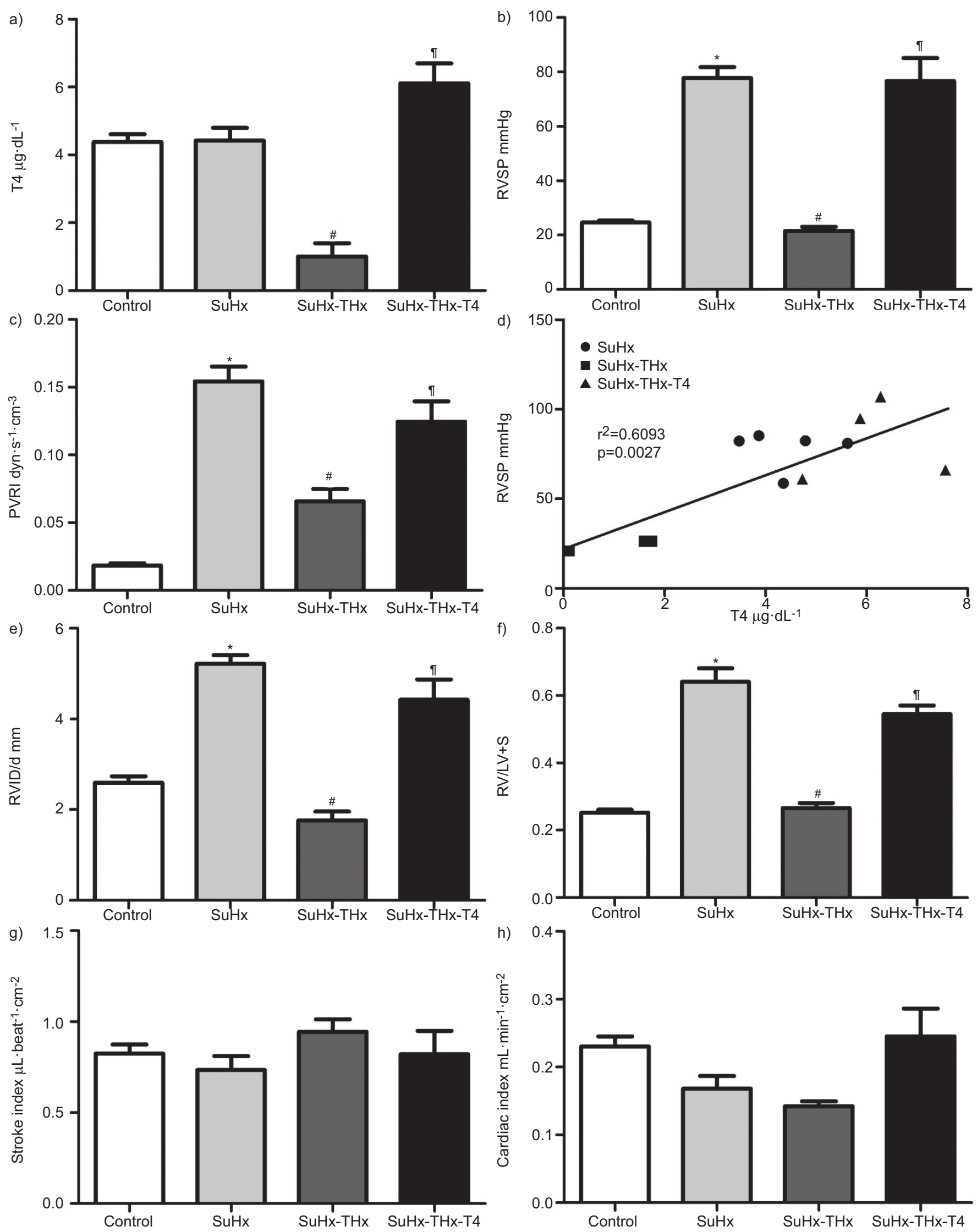

FIGURE 1. For figure legend see next page. 
FIGURE 1. The effects of subtotal thyroidectomy $(T H x)$ and subtotal thyroidectomy with replacement of thyroxin (THx+T4) in Sugen-chronic hypoxia (SuHx) rats on a) plasma T4 level, b) right ventricular systolic pressure (RVSP), c) pulmonary vascular resistance index (PVRI), e) right ventricular diameter, measured in diastole (RVID/d), f) right ventricular hypertrophy (right ventricular weight over left ventricular plus septal weight, or RV/LV+S), g) stroke index and h) cardiac index. d) The relationship between plasma T4 levels with RVSP. Data are presented as mean \pm SE $(n=5-8)$. *: $p<0.05$ versus control; ${ }^{*}: p<0.05$ versus SuHx; ${ }^{*}: p<0.05$ versus SuHx-THx.

expression of cleaved caspase 3 in SuHx lungs and thyroxin supplementation in thyroidectomised SuHx rats was related to increased expression of PCNA and cleaved caspase 3 (figs 4 and S3).

\section{The permissive effect of thyroid hormone on angio- obliteration in SuHx rats is associated with altered integrin $\alpha \mathbf{v} \beta 3$ and fibroblast growth factor-2 signalling}

Because one of the signalling pathways distal to cell membrane thyroid hormone receptors involves the angiogenic fibroblast growth factor (FGF)-2 and the integrin $\alpha \mathrm{v} \beta 3$ [11, 12], which is highly expressed in activated endothelial cells [23, 24], and because FGF-2 has been associated with severe PAH [25-27], we assessed the expression of this growth factor and integrin $\alpha v \beta 3$ in the lungs from animals that had developed severe PAH. Thyroidectomy reduced the protein expression of FGF-2, $\alpha v \beta 3$ integrins (fig. $4 \mathrm{a}-\mathrm{d}$ ) and phosphorylated-extracellular signal-regulated kinase (Erk) in the lung from SuHx animals (fig. 4a and h). Thyroxin supplementation in thyroidectomised $\mathrm{SuHx}$ animals restored the expression of FGF- 2 and of the $\alpha \mathrm{v} \beta 3$ integrin proteins to the levels observed in the SuHx animals (fig. 4). Figure 5 and figures S4-S7 demonstrate that FGF-2 and $\alpha v \beta 3$ proteins are overexpressed in lungs from SuHx rats and that overexpression does not occur in thyroidectomised animals. Lung tissue expression of the FGF-2 protein and the $\alpha \mathrm{v}$ integrin, and of PCNA and $\alpha \mathrm{v}$ integrin were correlated (fig. S3i and j), suggesting that in the setting of severe PH cell proliferation, FGF-2 expression and integrin expression are perhaps synchronised.

\section{PTU treatment of rats with established PH}

Having established that thyroidectomy prevents the development of angioproliferative PAH in the SuHx model, we next examined whether PTU would affect established PAH in the
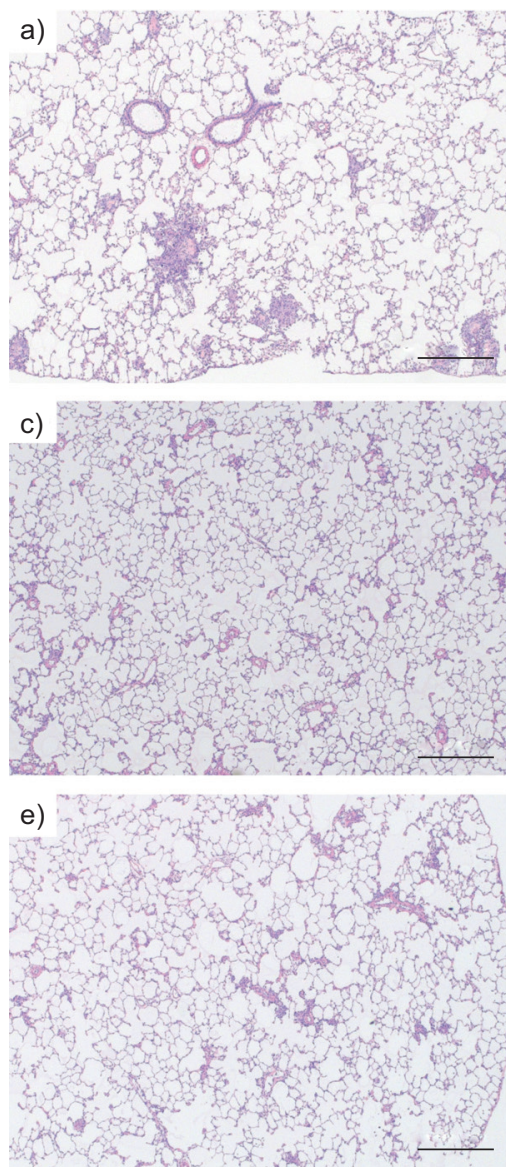
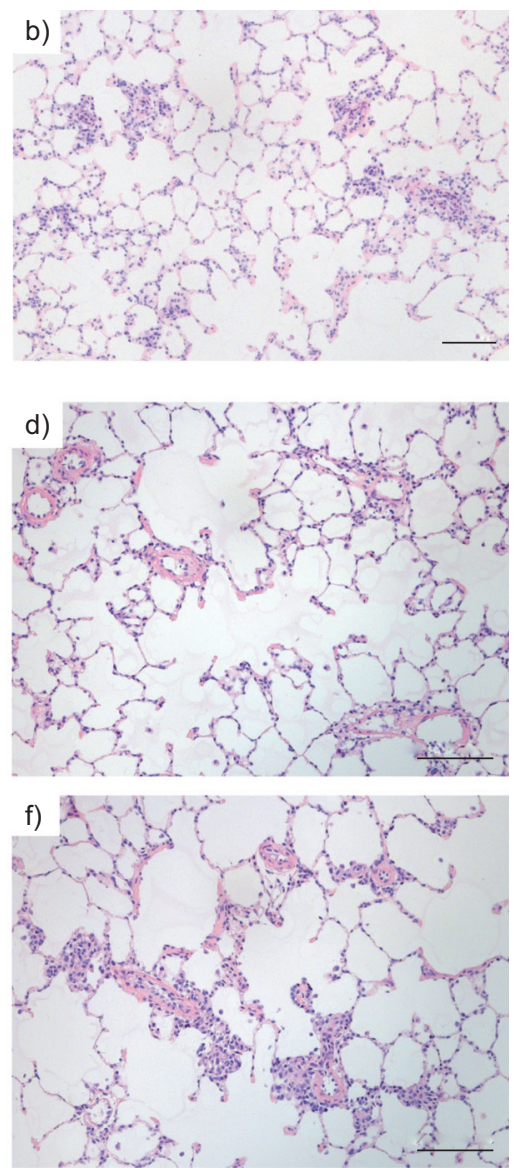
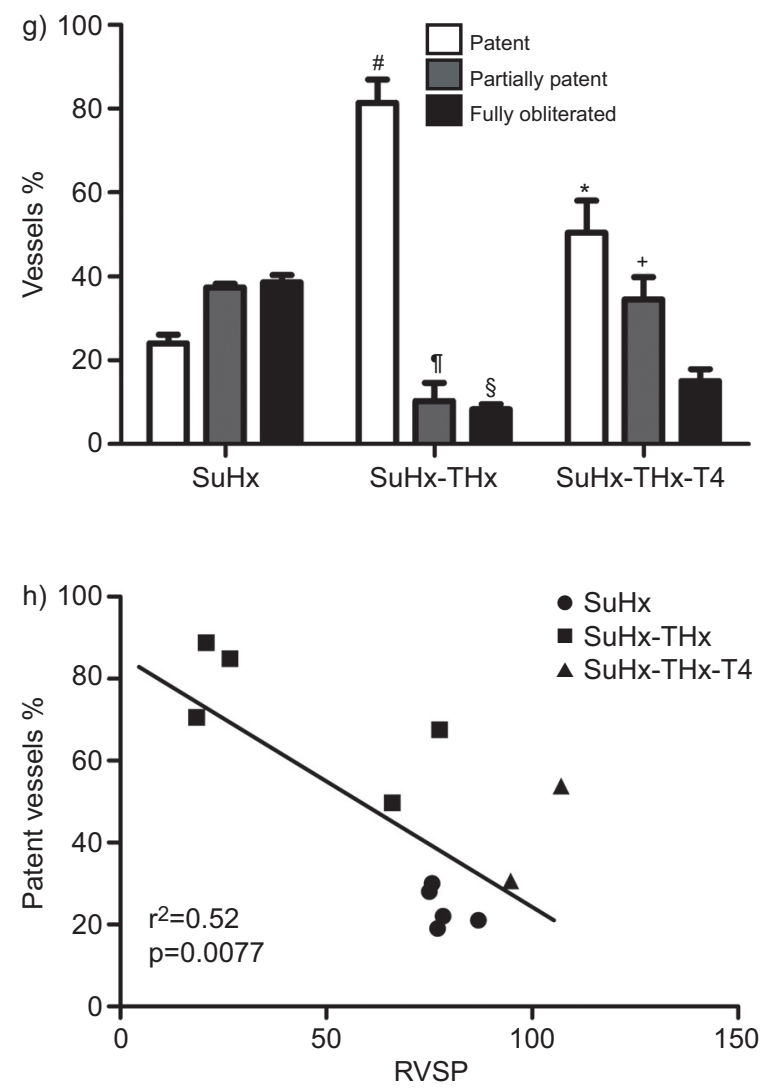

FIGURE 2. a-f) Representative photomicrograph of haematoxylin and eosin stained lung sections of $a$, b) Sugen-chronic hypoxia (SuHx) rat, $c$ and d) SuHx rat with thyroidectomy (THx) and e, f) SuHx rat with thyroidectomy plus thyroxin (T4) replacement. a, c, e) Scale bar=500 $\mu \mathrm{m}$; and b, d, f) scale bar=100 $\mu \mathrm{m}$. g) The percentage of small pulmonary arteries ( $<80 \mu \mathrm{m}$ in diameter) classified as patent, partially patent and fully obliterated. $\mathrm{h}$ ) The relationship between the percentage of patent vessels and right ventricular systolic pressure (RVSP). *: $p<0.05$ versus percentage of patent vessels in SuHx with thyroidectomy rats' lungs; ${ }^{*}: p<0.05$ versus percentage of patent vessels in SuHx rats' lungs; ': $p<0.05$ versus percentage of partially obliterated vessels in SuHx rats' lungs; ${ }^{+}: p<0.05$ versus percentage of partially obliterated vessels in SuHx with thyroidectomy rats' lungs; ${ }^{\text {s. }} p<0.05$ versus percentage of fully obliterated vessels in SuHx rats' lungs. Data are presented as mean \pm SE ( $\left.n=3-5\right)$. 

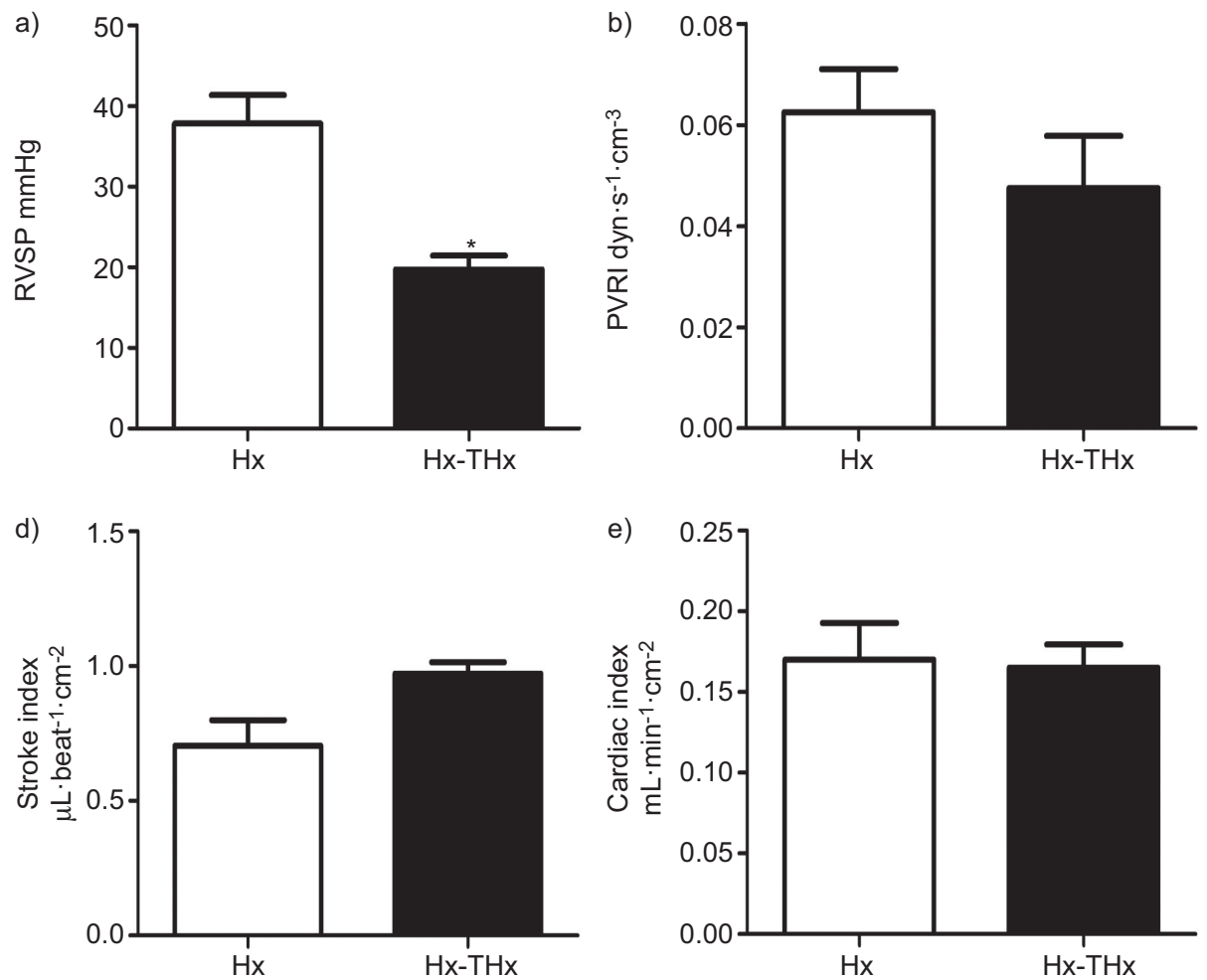
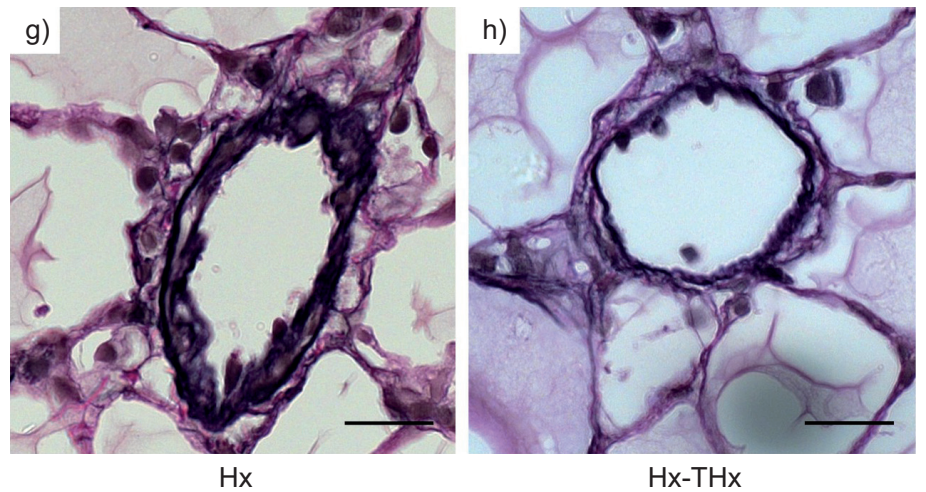

$\mathrm{Hx}-\mathrm{THx}$
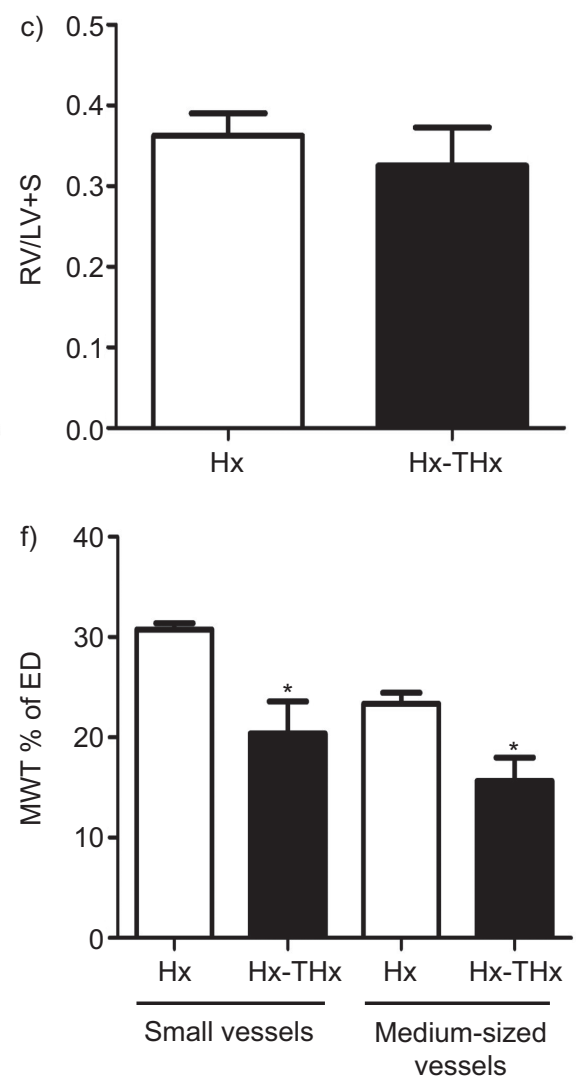

SuHx model. 4 weeks' treatment with daily dosing of PTU reduced the RVSP, PVRI and RV hypertrophy (fig. 6). These results show that reduction in thyroxin levels is not only able to prevent but also reverse, at least in part, $\mathrm{PH}$ and its consequences on the RV. Figure 7 shows that PTU treatment reduced the number of completely or partially occluded arterioles in the lung. In fact, the number of patent vessels correlated with the RVSP, and the number of obliterated vessels also related to the degree of RV hypertrophy. Figure $7 \mathrm{~g}$ shows the percentage of patent and obliterated arterioles. Similar to the thyroidectomised SuHx animals, PTU treatment resulted in a reduction in the number of PCNA positive cells (fig. S8). The expression of FGF-2 but not of the $\alpha v \beta 3$ protein was reduced in the lung tissues from the PTU treated animals (fig. S9). Thus, PTU treatment of SuHx rats with established $\mathrm{PAH}$ and lung arteriolar obliteration altered the tissue protein expression of growth and apoptosis-related factors in a direction similar to thyroidectomy.

\section{DISCUSSION}

Based on the knowledge that the thyroid hormones stimulate endothelial cell growth [11-13] and enhance hypoxic pulmonary vasoconstriction [14], we hypothesised that pulmonary vascular remodelling during the development of severe $\mathrm{PAH}$ is thyroid-hormone dependent. Here we show that induced hypothyroidism prevents and reverses vascular obliteration in the lungs of SuHx rats and mitigates hypoxic pulmonary vascular remodelling. Other important findings were that thyroidectomy and PTU treatment both reduced the high overexpression of the growth factor FGF-2 and integrin $\alpha \mathrm{v} \beta 3$ proteins, which characterise the SuHx lungs, and that prevention or treatment of PAH via modulating thyroxin leads to significantly less RV hypertrophy and dilatation.

Whereas the association of thyroid disorders with both idiopathic and non-idiopathic forms of $\mathrm{PH}$ has been well recognised, there is presently no stated hypothesis that 
a)

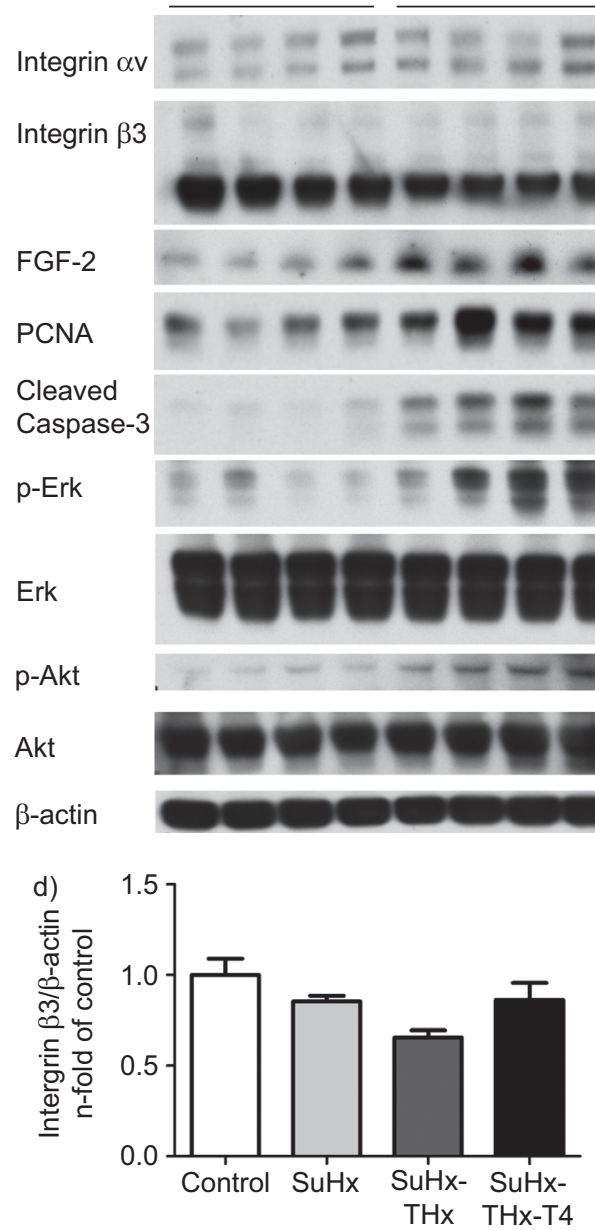

SuHx-THx SuHx-THx-T4

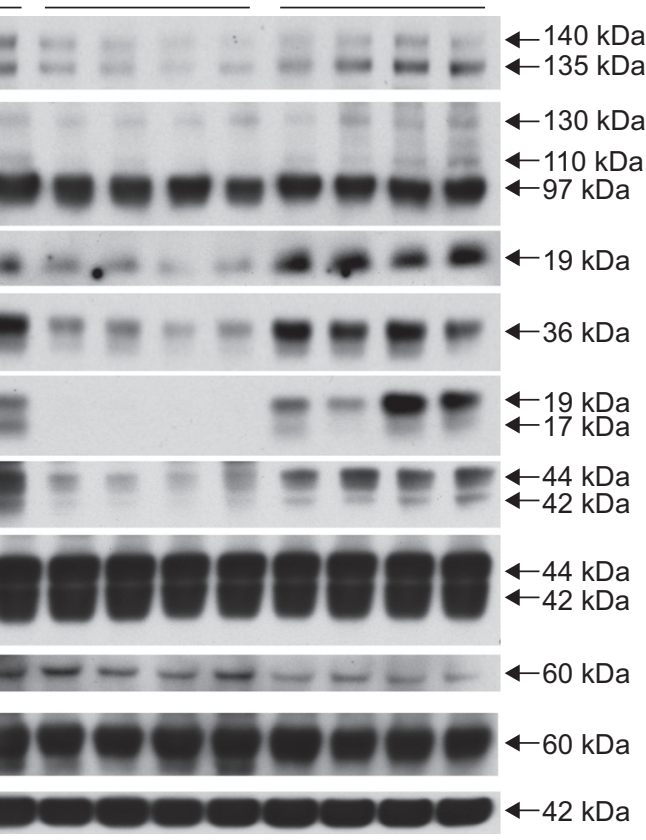

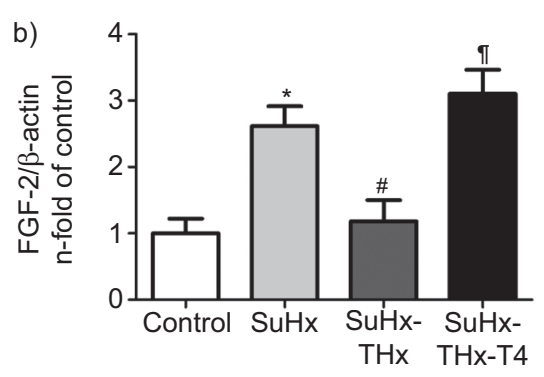
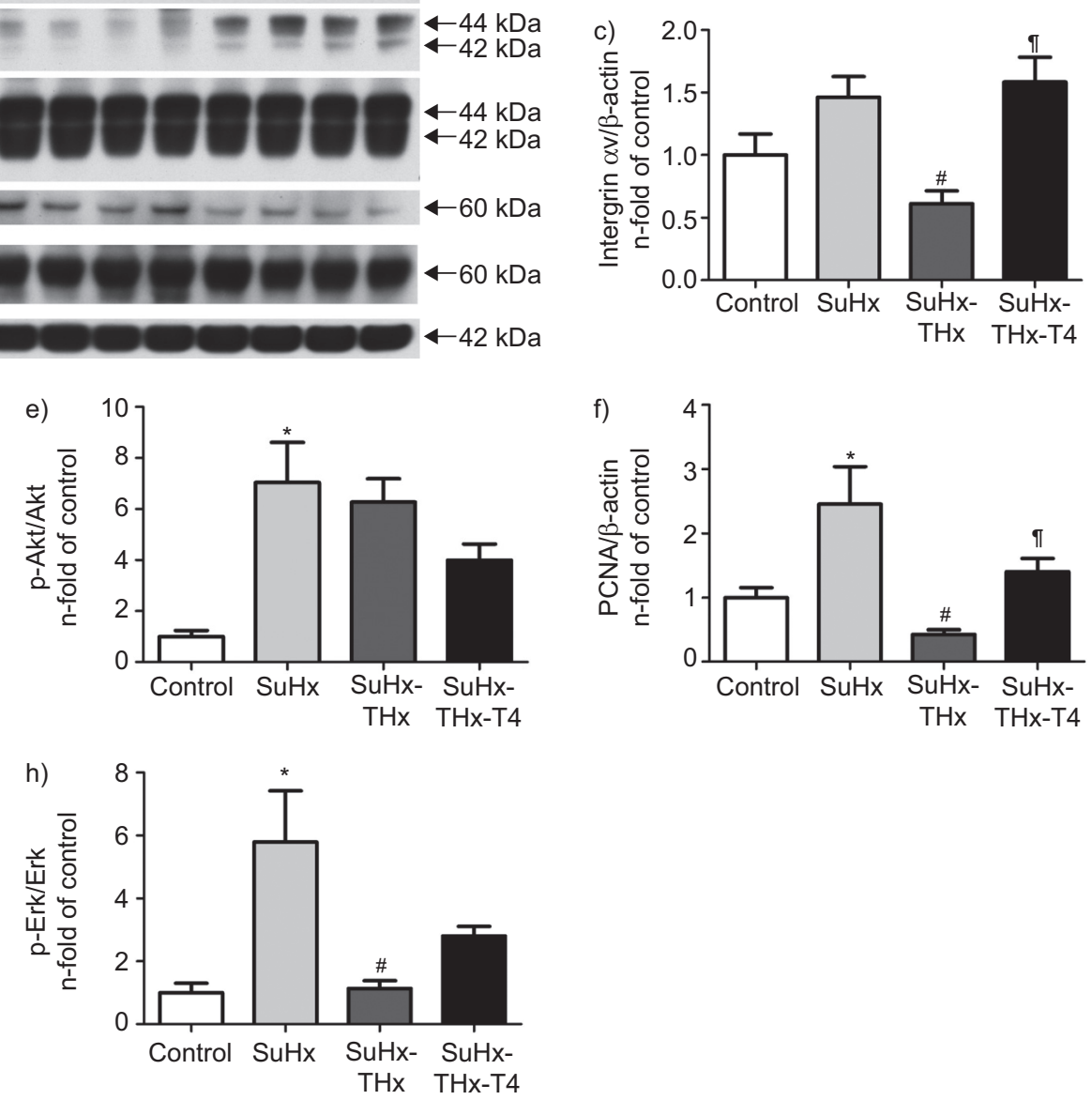

FIGURE 4. a) Representative western blot analysis of integrin $\alpha$, integrin $\beta 3$, fibroblast growth factor (FGF)-2, proliferating cell nuclear antigen (PCNA), cleaved caspase-3, phosphorylated-extracellular signal-regulated kinase ( $\mathrm{p}$-Erk), Erk, phospo-Akt ( $\mathrm{p}$-Akt), Akt and $\beta$-actin in lung protein extracts from control, Sugen-chronic hypoxia (SuHx), SuHx with thyroidectomy (THx) and SuHx with thyroidectomy and replaced with thyroxin (T4). Bar graphs showing the ratios of b) FGF-2, c) integrin $\alpha \mathrm{v}$, d) integrin $\beta 3$, e) $p$-Akt/Akt ratio, f) PCNA, g) cleaved caspase-3 and h) $p$-Erk/Erk ratio protein expression relative to controls. Data are presented as mean \pm SE ( $n=4)$. *: $p<0.05$ versus control; \#: $p<0.05$ versus SuHx; ${ }^{\circ}: p<0.05$ versus SuHx-THx.

attempts to explain how thyroid hormones influence the pathogenesis of pulmonary vascular disorders. Several publications document a prevalence of hypothyroidism of $\sim 30 \%$ in patients with PAH [28-30]. Given the significant overlap between idiopathic PAH (IPAH) and autoimmune disorders, one hypothesis is that the cause of hypothyroidism in patients with IPAH is an autoimmune thyroiditis [31]. There is also a strong association between hyperthyroidism and $\mathrm{PH}$ (table S1). It is unclear whether PH in hyperthyroid patients relates to left heart disease, a hyperdynamic circulation or a permissive effect of thyroid hormones on pulmonary vascular remodelling [11, 12]. The possible clinical translations of our findings are as follows: 1) we found no evidence for a cause-effect relationship between hypothyroidism and $\mathrm{PAH} ; 2$ ) thyroid hormone replacement in hypothyroid PAH patients should probably be performed cautiously, to avoid enhanced vascular remodelling; and 3) hyperthyroidism may accelerate pre-capillary forms of $\mathrm{PH}$.

The mechanisms underlying pulmonary arterial muscularisation and lumen occlusion in $\mathrm{SuHx}$ rats are undoubtedly 

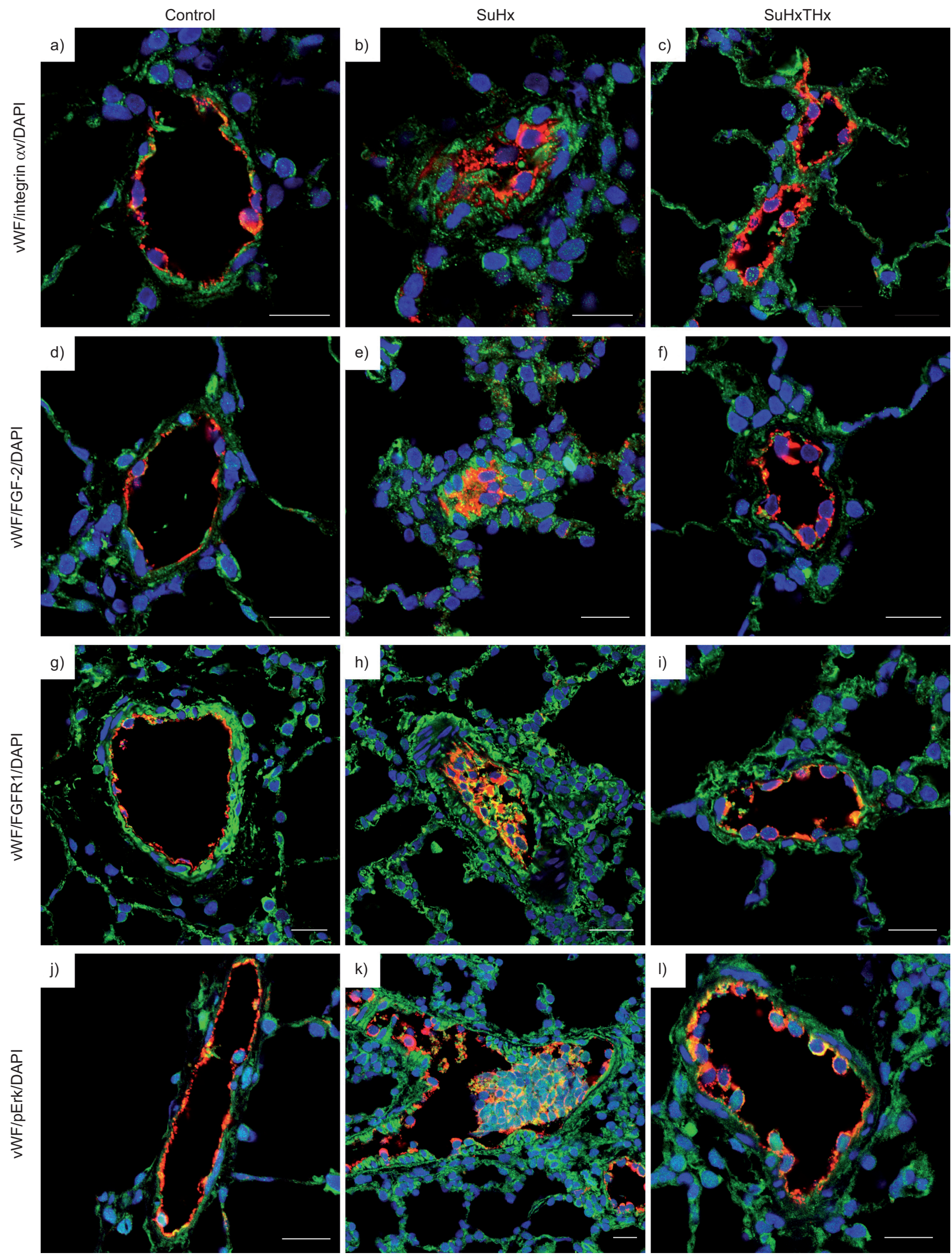

FIGURE 5. For figure legend see next page. 
FIGURE 5. Representative optical sections acquired by confocal microscopy of double immunofluorescence stainings for von Willebrand factor (VWF; red), integrin $\alpha v$ (green), fibroblast growth factor (FGF)-2 (green), FGF receptor (R)1 (green) and phosphorylated-extracellular signal-regulated kinase (p-Erk)1/2 (green). Nuclear counterstaining with DAPI (blue). Scale bars $=20 \mu \mathrm{m}$. a-c) vWF/integrin $\alpha v$ double immunofluorescence staining shows increased $\alpha v$ integrin staining in lumen occluding $\mathrm{VWF}^{+}$) cells, media layer cells and surrounding cellular infiltrate and alveolar cells of b) Sugen-chronic hypoxia (SuHx) animals, whereas less $\alpha v$ integrin staining is found in and around vessels of a) control and c) SuHx/thyroidectomised (THx) animals. d-f) vWF/FGF-2 double immunofluorescence staining demonstrates elevated FGF-2 staining predominantly in lumen occluding VWF $^{+}$cells, but also in media layer cells and surrounding cellular infiltrate and alveolar cells of e) SuHx animals, whereas FGF-2 is found less in and around vessels of d) control and f) SuHxTHx animals. g-i) vWF/FGFR1 double immunofluorescence staining reveals extensive immunoreactivity for FGFR1 in lumen occluding $\mathrm{VWF}^{+}$cells, media layer cells and surrounding cellular infiltrate and alveolar cells of $\mathrm{h}$ ) SuHx animals, whereas less FGFR1 staining is found in and around vessels of g) control and i) SuHxThx animals. j-I) VWF/p-Erk1/2 double immunofluorescence staining clearly demonstrates multiple lumen occluding vWF ${ }^{+}$cells exhibiting strong nuclear and cytoplasmatic p-Erk1/2 staining in an angioproliferative lesion of $\mathrm{k}$ ) SuHx animals, whereas less $\mathrm{VWF}^{+} / \mathrm{pErk} 1 / 2^{+}$cells are found in vessels of j) control and I) SuHxThx animals. Note the highly increased p-Erk1/2 staining in media layer cells, infiltrating and alveolar cells of SuHx animals as compared to control and SuHxThx animals Also note the difference in endothelial (VWF', red) morphology between control animals (flat nucleus) and SuHxThx animals (round, activated nucleus) in images a-l).

complex and guided by multicellular interactions. Here we focused our attention on apoptosis and cell growth signals expressed by lumen filling cells and in perivascular cellular clusters. In thyroidectomised SuHx rats, only a few cells coating the luminal surface of the arterioles by IHC expressed PCNA and cleaved caspase 3 (fig. S2) when compared with the lung sections from pulmonary hypertensive SuHx animals. These results were supported by analysis of whole lung tissue PCNA and cleaved caspase 3 protein expression (fig. 4). Taken together with the data derived from thyroidectomised SuHx rats that received thyroxin supplementation (fig. 2), our data indicate that indeed thyroxin drives lumen obliterating cell growth in the setting of severe PAH. The mitigation of hypoxic pulmonary vascular remodelling after thyroidectomy suggests that thyroxin is also permissive for pulmonary artery smooth muscle cell hypertrophy. Our studies were not designed to determine the exact nature of smooth muscle and endothelial cell interactions in the SuHx model of experimental PAH. The trend of a reduced PVRI in thyroidectomised hypoxic rats was not tracked by a reduction in RV hypertrophy, which was unexpected but perhaps related to an unpredictable effect of hypothyroidism on cardiomyocyte hypertrophy.

We had postulated that the angiogenesis factor FGF-2 and signalling via Erk might be involved in the mechanism of thyroid hormone-related vascular remodelling in our animal model [11]. Examining random lung tissue samples, the expression of FGF-2 and p-Erk was clearly thyroid hormone dependent. By IHC analysis we found that FGF-2, FGF receptor (R)1 and p-Erk were expressed in lung vascular lesion cells and that the expression of these proteins in the lesions was affected by thyroidectomy and thyroxin replacement treatment. In a similar fashion, lung tissue expression of the integrin protein $\alpha \mathrm{v}$ was decreased in thyroidectomised SuHx rat lungs and its expression was restored following thyroxin replacement (fig. 4c), while the expression changes for the $\beta 3$ chain were less pronounced (fig. 4d). Having observed the thyroid hormone-dependent pulmonary vascular remodelling changes in thyroidectomised rats, we assessed the effect of PTU treatment on established PAH and on lung vessel remodelling. We have shown that PTU treatment reduced the
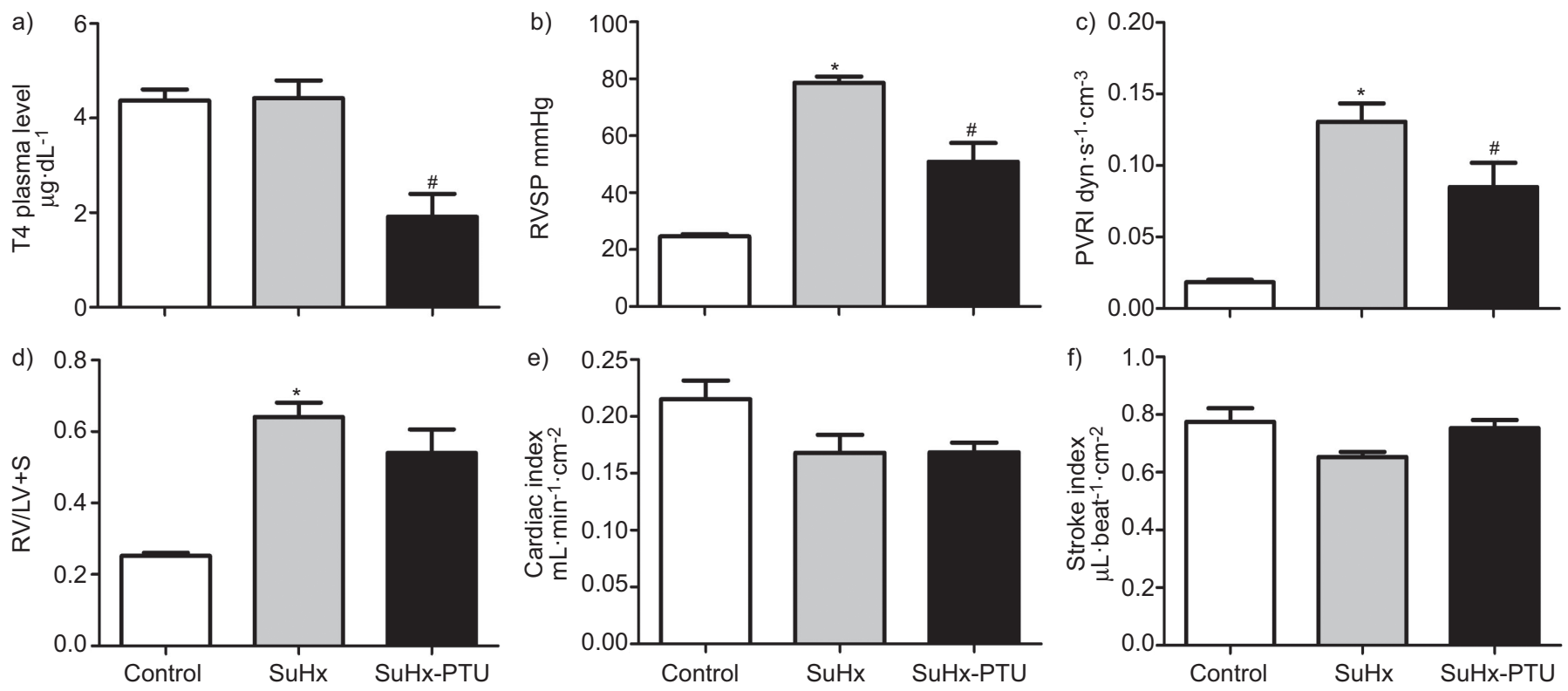

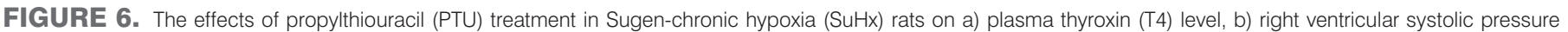

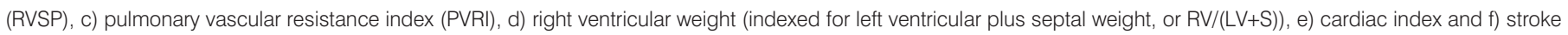
index. Data are presented as mean \pm SE $(n=5-8)$. *: $p<0.05$ versus control; ${ }^{*}: p<0.05$ versus SuHx. 

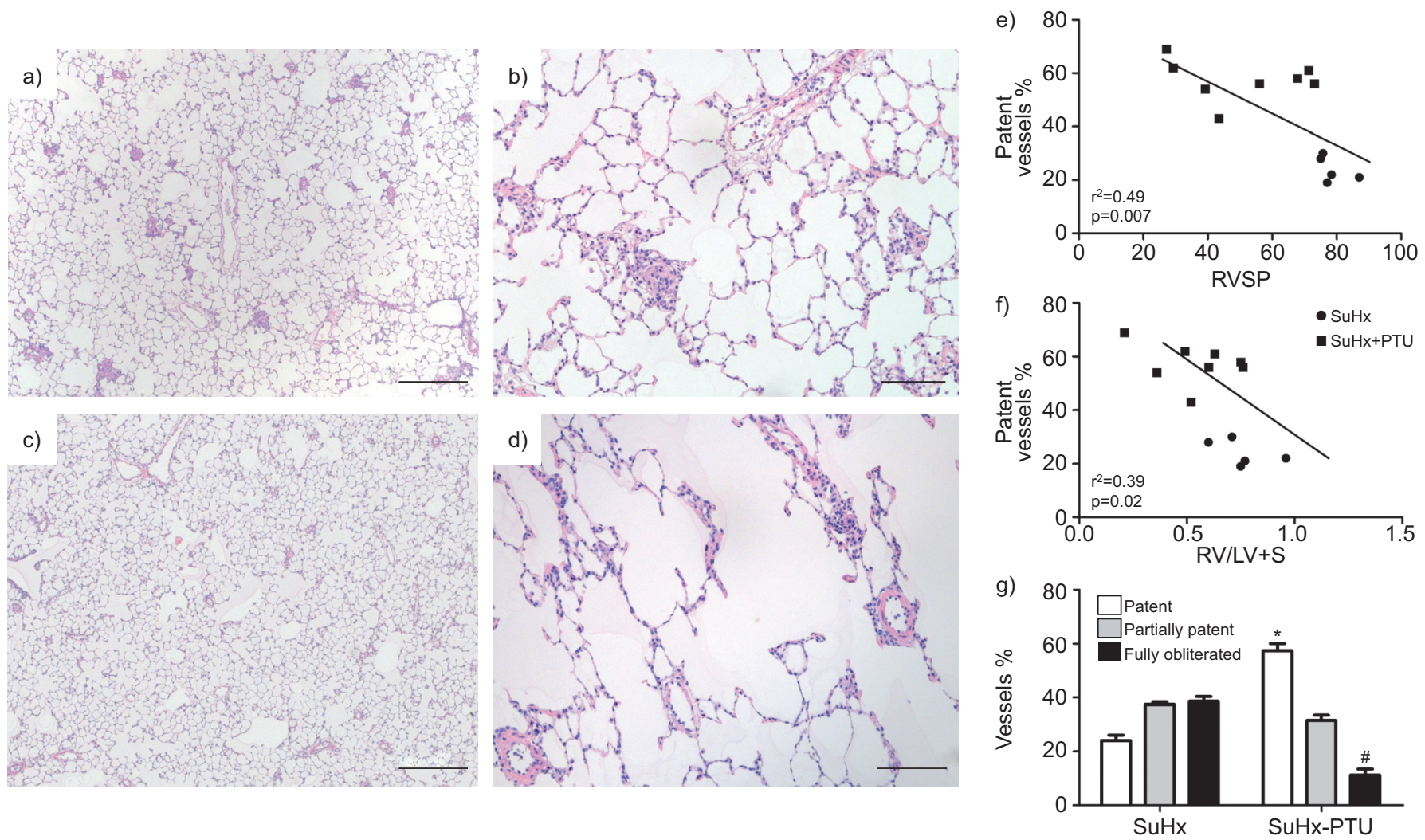

FIGURE 7. Representative photomicrographs of haematoxylin and eosing-stained lung sections of a, b) Sugen-chronic hypoxia (SuHx) rats and c, d) SuHx rats treated with propylthiouracil (PTU). a, c) Scale bar=500 $\mu \mathrm{m} ; \mathrm{b}, \mathrm{d}) \mathrm{scale}$ bar=100 $\mu \mathrm{m}$. Relationship between percentage of patent vessels and e) right ventricular systolic pressure (RVSP) and f) right ventricular (RV) hypertrophy (RV weight over left ventricular (LV) plus septal (S) weight, or RV/(LV+S)). g) Percentage of small pulmonary arteries (<80 $\mu m$ in diameter) classified as patent, partially patent and fully obliterated. Data are presented as mean $\pm S E(n=5-8)$. *: $p<0.05$ versus percentage of patent vessels in SuHx rats lung; ${ }^{\#}: \mathrm{p}<0.05$ versus fully obliterated vessels in SuHx rats' lung.

RVSP and PVR, thereby reducing RV hypertrophy, although the effects of PTU were substantially smaller than the preventative effects of thyroidectomy (fig. 5). PTU treatment reopened obliterated arterioles, the number of patent vessels in the lungs from PTU-treated SuHx lungs had increased and this greater degree of vessel patency correlated with the RVSP (fig. 6). Whereas PTU treatment clearly reduced the expression of the angiogenesis factor FGF-2, in the SuHx lungs the effect of PTU treatment on $\alpha v \beta 3$ expression was insignificant (fig. S9), suggesting that perhaps in the SuHx lungs FGF-2 expression depends on the action of thyroid hormone. A potential pathogenetic role for FGF-2 in PAH has been proposed by IZIKKI et al. [26] and FGF-2 expression in human lung vascular lesions has been described previously [27]. Here we show that in the setting of the VEGF receptor blockade and chronic hypoxia, FGF-2 is highly expressed in the lung tissue samples and propose that FGF-2 is angiogenic in the SuHx model of $\mathrm{PAH}$. Measurement of plasma thyroxin concentrations revealed that both thyroidectomy and PTU treatment reduced the thyroxin levels, SU5416 combined with chronic hypoxia did not increase plasma thyroxin levels and that thyroxin replacement of thyroidectomised SuHx rats restored the thyroxin levels to normal or slightly more than normal. Thus in the SuHx animals, the plasma thyroxin levels correlated with the RVSP (fig. 1d).
The angiogenic actions of thyroid hormones in our SuHx rat model of angio-obliterative severe PAH may be explained via thyroid hormone cell membrane receptor signalling [32]. Under conditions of chronic VEGF receptor blockade (caused by SU5416), FGF-2 becomes over-expressed and integrin $\alpha \mathrm{v} \beta 3$ may function as a signalling modulator for both FGF-2 [33] and the thyroid hormones [11]. In cell experiments, the growth promoting actions of FGF-2 and of thyroxin have been inhibited by a mitogen-activated protein kinase inhibitor (PD-98059) [11]. In particular, BERGH et al. [12] have shown that integrin $\alpha \mathrm{v} \beta 3$ contains cell surface receptor binding sites for thyroxin that are linked to MAP-kinase activation, whereas a separate binding domain on the $\alpha \mathrm{v} \beta 3$ integrin links to phosphoinositide 3-kinase and may contribute to cell growth signalling via activation of nuclear hypoxia-inducible factor- $1 \alpha$ [32]. Whether these cell signalling events of thyroxin that have been worked out in cultured endothelial cells $[11,12,32]$ to explain the angiogenic actions of thyroxin are indeed applicable to the thyroid hormone-dependent angioproliferation in our SuHx model is presently unknown and will have to be examined in future experiments.

\section{Study limitations}

The descriptive nature of our studies precludes definite conclusions regarding the exact mechanism of thyroid 
hormone-related angioproliferative remodelling. Because mouse models of $\mathrm{PH}$ lack a consistent angioproliferative component [34], our research, by necessity, makes exclusive use of rat models, thereby limiting the possibility to use transgenic interventions. In contrast to the strong evidence provided by our study for a role of thyroid hormones in the initial development of angioproliferative remodelling, the role of thyroid hormones in disease maintenance is less clear. PTU partially reversed the increase in pulmonary artery pressures, but the effect was relatively small in comparison to the preventive effect of thyroidectomy. This study provides no explanation for the frequently reported association between hypothyroidism and $\mathrm{PH}$. Rather, the results suggest that this association is more likely to be the result of the link between both conditions and auto-immunity [31].

In conclusion, in this report we show for the first time that in experimental $\mathrm{PAH}$, thyroid hormones are highly permissive to the development of severe angio-obliterative $\mathrm{PAH}$ and contribute to the injury response of lung vessels when lung vascular endothelial cells undergo apoptosis [16]. The thyroid hormone attributable angioproliferative component may not require elevated plasma hormone levels but rather may depend on facilitated thyroid hormone cell membrane receptor ( $\alpha$ v $\beta 3$ integrin) signalling [32].

\section{SUPPORT STATEMENT}

Support for this study was obtained from the Victoria Johnson Center for Pulmonary Obstructive Research at the Virginia Commonwealth University, Richmond, VA, USA.

\section{STATEMENT OF INTEREST}

A statement of interest for N.F Voelkel can be found at www.erj. ersjournals.com/site/misc/statements.xhtml

\section{ACKNOWLEDGEMENTS}

The authors wish to thank V. Kraskauskasiene for help with the thyroid hormone measurements and D. Gardner (both at Dept of Medicine, Virginia Commonwealth University, Richmond, VA, USA) for critically reading the manuscript.

\section{REFERENCES}

1 Tuder RM, Groves B, Badesch DB, et al. Exuberant endothelial cell growth and elements of inflammation are present in plexiform lesions of pulmonary hypertension. Am J Pathol 1994; 144: 275-285.

2 Xu W, Koeck T, Lara AR, et al. Alterations of cellular bioenergetics in pulmonary artery endothelial cells. Proc Natl Acad Sci USA 2007; 104: 1342-1347.

3 Macchia A, Marchioli R, Marfisi R, et al. A meta-analysis of trials of pulmonary hypertension: a clinical condition looking for drugs and research methodology. Am Heart J 2007; 153: 1037-1047.

4 Rai PR, Cool CD, King JA, et al. The cancer paradigm of severe angioproliferative pulmonary hypertension. Am J Respir Crit Care Med 2008; 178: 558-564.

5 Simonneau G, Robbins IM, Beghetti M, et al. Updated clinical classification of pulmonary hypertension. J Am Coll Cardiol 2009; 54: Suppl. 1, S43-S54.

6 Galiè N, Hoeper MM, Humbert M, et al. Guidelines for the diagnosis and treatment of pulmonary hypertension. The Task Force for the Diagnosis and Treatment of Pulmonary Hypertension of the European Society of Cardiology (ESC) and the European Respiratory Society (ERS) endorsed by the
International Society of Heart and Lung Transplantation (ISHLT). Eur Respir J 2009; 34: 1219-1263.

7 Tyndall AJ, Bannert B, Vonk M, et al. Causes and risk factors for death in systemic sclerosis: a study from the EULAR Scleroderma Trials and Research (EUSTAR) database. Ann Rheum Dis 2010; 69: 1809-1815.

8 Gladwin MT, Sachdev V, Jison ML, et al. Pulmonary hypertension as a risk factor for death in patients with sickle cell disease. $N$ Engl J Med 2004; 350: 886-895.

9 Humbert M, Sitbon O, Chaouat A, et al. Survival in patients with idiopathic, familial, and anorexigen-associated pulmonary arterial hypertension in the modern management era. Circulation 2010; 122: $156-163$.

10 Biondi B, Kahaly GJ. Cardiovascular involvement in patients with different causes of hyperthyroidism. Nat Rev Endocrinol 2010; 6: 431-443.

11 Davis FB, Mousa SA, O'Connor L, et al. Proangiogenic action of thyroid hormone is fibroblast growth factor-dependent and is initiated at the cell surface. Circ Res 2004; 94: 1500-1506.

12 Bergh JJ, Lin HY, Lansing L, et al. Integrin alphaVbeta3 contains a cell surface receptor site for thyroid hormone that is linked to activation of mitogen-activated protein kinase and induction of angiogenesis. Endocrinology 2005; 146: 2864-2871.

13 Davis PJ, Davis FB, Mousa SA. Thyroid hormone-induced angiogenesis. Curr Cardiol Rev 2009; 5: 12-16.

14 Herget J, Frydrychova M, Kawikova I, et al. Thyroxine treatment increases the hypoxic pulmonary vasoconstriction in isolated lungs from thyroidectomized rats. Bull Eur Physiopathol Respir 1987; 23: 217-221.

15 Oka M, Homma N, Taraseviciene-Stewart L, et al. Rho kinasemediated vasoconstriction is important in severe occlusive pulmonary arterial hypertension in rats. Circ Res 2007; 100: 923-929.

16 Taraseviciene-Stewart L, Kasahara Y, Alger L, et al. Inhibition of the VEGF receptor 2 combined with chronic hypoxia causes cell death-dependent pulmonary endothelial cell proliferation and severe pulmonary hypertension. FASEB J 2001; 15: 427-438.

17 Bogaard HJ, Natarajan R, Henderson SC, et al. Chronic pulmonary artery pressure elevation is insufficient to explain right heart failure. Circulation 2009; 120: 1951-1960.

18 Pass D, Freeth G. The rat. ANZCCART News 1993; 6: 1-4.

19 Chemla D, Castelain V, Humbert M, et al. New formula for predicting mean pulmonary artery pressure using systolic pulmonary artery pressure. Chest 2004; 126: 1313-1317.

20 Richalet JP, Letournel M, Souberbielle JC. Effects of high-altitude hypoxia on the hormonal response to hypothalamic factors. Am J Physiol Regul Integr Comp Physiol 2010; 299: R1685-R1692.

21 Moncloa F, Guerra-Garcia R, Subauste C, et al. Endocrine studies at high altitude. I. Thyroid function in sea level natives exposed for two weeks to an altitude of 4300 meters. J Clin Endocrinol Metab 1966; 26: 1237-1239.

22 Zayour D, Azar ST, Azar N, et al. Endocrine changes in a rat model of chronic hypoxia mimicking cyanotic heart disease. Endocr Res 2003; 29: 191-200.

23 Cai W, Chen X. Anti-angiogenic cancer therapy based on integrin alphavbeta3 antagonism. Anticancer Agents Med Chem 2006; 6: 407-428.

24 Tanghetti E, Ria R, Dell'Era P, et al. Biological activity of substratebound basic fibroblast growth factor (FGF2): recruitment of FGF receptor-1 in endothelial cell adhesion contacts. Oncogene 2002; 21: 3889-3897.

25 Benisty JI, McLaughlin VV, Landzberg MJ, et al. Elevated basic fibroblast growth factor levels in patients with pulmonary arterial hypertension. Chest 2004; 126: 1255-1261.

26 Izikki M, Guignabert C, Fadel E, et al. Endothelial-derived FGF2 contributes to the progression of pulmonary hypertension in humans and rodents. J Clin Invest 2009; 119: 512-523. 
$27 \mathrm{Tu} \mathrm{L}$, Dewachter L, Gore B, et al. Autocrine fibroblast growth factor-2 signaling contributes to altered endothelial phenotype in pulmonary hypertension. Am J Respir Cell Mol Biol 2011; 45: 311-322.

28 Badesch DB, Wynne KM, Bonvallet S, et al. Hypothyroidism and primary pulmonary hypertension: an autoimmune pathogenetic link? Ann Intern Med 1993; 119: 44-46.

29 Curnock AL, Dweik RA, Higgins BH, et al. High prevalence of hypothyroidism in patients with primary pulmonary hypertension. Am J Med Sci 1999; 318: 289-292.

$30 \mathrm{Chu}$ JW, Kao PN, Faul JL, et al. High prevalence of autoimmune thyroid disease in pulmonary arterial hypertension. Chest 2002; 122: $1668-1673$.
31 Nicolls MR, Taraseviciene-Stewart L, Rai PR, et al. Autoimmunity and pulmonary hypertension: a perspective. Eur Respir J 2005; 26: 1110-1118.

32 Cheng SY, Leonard JL, Davis PJ. Molecular aspects of thyroid hormone actions. Endocr Rev 2010; 31: 139-170.

33 Rusnati M, Tanghetti E, Dell'Era P, et al. alphavbeta3 integrin mediates the cell-adhesive capacity and biological activity of basic fibroblast growth factor (FGF-2) in cultured endothelial cells. Mol Biol Cell 1997; 8: 2449-2461.

34 Gomez-Arroyo JG, Saleem SJ, Mizuno S, et al. A brief overview of mouse models of pulmonary arterial hypertension: problems and prospects. Am J Physiol Lung Cell Mol Physiol 2012; 302: L977-L991. 